ARTICLE

https://doi.org/10.1057/s41599-019-0303-0

\title{
The evidence ecosystem in South Africa: growing resilience and institutionalisation of evidence use
}

\author{
Ruth Stewart (10) ${ }^{1,2}$, Harsha Dayal ${ }^{1,3}$, Laurenz Langer ${ }^{1} \&$ Carina van Rooyen ${ }^{1}$
}

\begin{abstract}
The evidence-informed approach to policy-making and implementation is, at its core, about better decisions for a better future. It is focused on the effective use of scarce resources, on avoiding harm and maximising good. It is grounded in principles of equity and equality, of accountability and transparency. Given these characteristics, for those of us who work in this field, there is arguably a moral, economic, social and political case for paying closer attention to evidence-informed decision-making ecosystems in the South. Evidencebased policy and implementation, or evidence-informed decision-making in line with the most recent thinking, is often framed from two inter-related but limited perspectives: first, it is viewed as an approach that has originated from 'developed' Northern countries, and second, it is conceptualised as a technical intervention. However, there has been a shift in how the approach is conceived, moving away from assumptions that it is an intervention implemented from outside, from the North, for the benefit of the South. As part of this shift, certain initiatives in Africa have gained greater momentum. It is in acknowledging that there are different ways to think (epistemic diversity) about Southern evidence-informed decisionmaking, that this work has arisen. It seizes on the opportunity to view evidence-informed decision-making in a new light, exploring the evidence ecosystems in the South as systems strongly influenced by, but not defined by, Northern stimuli, including, but not limited to, technical interventions. This work set out to describe the evidence ecosystem in South Africa. In doing so, it finds that the ecosystem is increasingly resilient despite some limitations. It has strong structural foundations, includes many diverse organisations, is supported by not inconsiderable investment, is enabled by growing and significant capacity, contains iterations and innovations, and last but not least, incorporates complexity that gives the ecosystem resilience. The work demonstrates, through its focus on South Africa's evidence ecosystem, that the global movement has much to learn from the South.
\end{abstract}

\footnotetext{
${ }^{1}$ Africa Centre for Evidence, University of Johannesburg, Johannesburg, South Africa. ${ }^{2}$ EPPI-Centre, UCL: Institute of Education, London, UK. ${ }^{3}$ Department for Planning, Monitoring and Evaluation, National Government, Pretoria, South Africa. Correspondence and requests for materials should be addressed to R.S. (email: ruths@uj.ac.za)
} 


\section{Background}

he evidence-informed approach to policy-making and implementation is, at its core, about better decisions for a better future. It is focussed on the effective use of scarce resources, on avoiding harm and maximising good. It is grounded in principles of equity and equality, of accountability and transparency.

Given these characteristics, for those of us who work in this field there is arguably a moral, economic, social and political case for paying closer attention to evidence-informed decision-making ecosystems in the South. Evidence-based policy and implementation, or evidence-informed decision-making in line with the most recent thinking, is often framed from two inter-related but limited perspectives: first, it is viewed as an approach that has originated from 'developed' Northern countries (White, 2019; Oliver et al., 2015), and second, it is conceptualised as a technical intervention (Guyatt et al., 1992). These perspectives are in part due to the strength of the evidence-based medicine field over the last 30 years, and the tendency within that field to adopt technical, intervention-based thinking. Further it has been strongly associated with the UK and Tony Blair's campaign slogan of 'what matters is what works' and his underlying drive for greater efficiencies (Davies et al., 1999). Within that political movement, the evidence-based approach was characterised by technical skills and management interventions.

However, there has been a shift in how the approach is conceived, moving away from assumptions that it is an intervention implemented from outside, from the North, for the benefit of the South. As part of this shift, certain initiatives in Africa have gained greater momentum (see for example: Nabyonga-Orem and Mijumbi, 2015; Stewart et al., 2018a). These initiatives, to a large extent, have been supported by high-profile champions from the North, and by an investment in country offices in the South by Northern bodies. We have seen increasing exposure in the literature for the use of the approach in the South, such as the use of evidence in developing a policy of free healthcare for children under five and women in Burkina Faso (Ridde and Yaméogo, 2018), the development of rapid response services in Uganda (Mijumbi et al., 2014), and the use of mentorship support to increase the use of evidence in Malawi and South Africa (Jordaan et al., 2018; Stewart et al., 2018b). We increasingly read about work of Southern organisations, including think tanks such as AFIDEP (Oronje and Zulu, 2018), and networks such as the Africa Evidence Network (Stewart, 2018).

However, it would be incomplete to merely celebrate Southern adoption of a Northern approach to evidence use in decisionmaking. There is a much broader and fundamental transformation underway in South Africa and across the continent of which we need to be cognisant. The influence of colonial history and the ways in which it has pervaded not only current structures but our ways of thinking and being, are now widely acknowledged. The challenge of de-coloniality is bringing to the surface a new recognition that very little, and certainly not the evidence-based approach, is new to the South. Instead, movements such as 'Made in Africa', spearheaded by the African Evaluation Association, have gained traction. This is a new way of considering what is 'home grown' and valuable in the South. The emphasis on local knowledge, goes beyond consideration of 'traditional' or 'cultural' perspectives in decision-making. It puts front and centre what is already in place, and organically developing from a value-driven perspective, above and beyond the adoption of ideas and innovations from elsewhere. It recognises that Northern terminology and conceptualisation may be in fashion and dominate existing ways of describing something, but that does not mean that the practice itself is new.
These broader shifts away from a deficit model in which the South needs rescuing by the North, help us to explain why young democracies that want to assert themselves reject some approaches, and choose to align themselves instead with those that are sensitive to their desire to evolve from within and not merely adopt from outside. If we recognise that the use of different forms of knowledge, or 'evidence' for want of a better word, in decisionmaking in the South has existed in various forms for many decades, then we shift our thinking away from merely a technical perspective and view the approach using political, social, as well as technical lenses. Here networks, trusting relationships and partnerships matter, even if difficult to measure (Stewart, 2018), as we will discuss further.

It is in acknowledging that there are different ways to think (epistemic diversity) about Southern evidence-informed decisionmaking, that this work has arisen. It seizes on the opportunity to view evidence-informed decision-making in a new light, exploring the evidence ecosystems in the South as systems strongly influenced by, but not defined by, Northern stimuli, including, but not limited to, technical interventions. It is a challenge for anyone to describe the complexities of a system across a region, and we are painfully aware that much of what we have proposed thus far leans towards generalisation. Aware that there are numerous evidence ecosystems in the region, at various levels and in various sectors, and to avoid the risk of misrepresenting our colleagues' work in the wider region, we set out to describe the evidence ecosystem at national level within the country in which we work, South Africa. Whilst we recognise that we cannot capture everything even within these parameters, we are able to provide a high-level overview and identify broad trends within the system.

As a middle-income country, South Africa is facing triple challenges of poverty, inequality, and unemployment, with the highest Gini coefficient in the world, an indicator of the level of economic inequality within the country (World Bank, 2018). Despite this, it has one of the largest economies in Africa (International Monetary Fund, 2018), and possibly one of the most vibrant science sectors, predominantly supported by state funding (Mail and Guardian, 2017). Its relatively recent political transformation post-apartheid presents challenges for this young democracy, as well as opportunities for better policies and a better future. It is this combination of need (extreme levels of inequality), opportunity (a strong research and development sector) and motivation (to build a new and better country) that makes South Africa an ideal case for exploring an evidence ecosystem.

Exploring the use of evidence in terms of the whole, rather than just parts thereof, is an attractive proposition, and helps us to move away from the limitations of the technical intervention lens. The term 'evidence ecosystem' is increasingly referred to, although not yet well defined (Elliott et al., 2014; Shepherd, 2014). If we draw on environmental science, ecosystem refers to the community of living and non-living components in an environment. They are linked by nutrient cycles and energy flows, and are influenced by both internal and external factors. They are dynamic and must adapt to changes. Their ability to adapt provides resilience within the system. It is this resilience and dynamism that is the core strength of an ecosystem for its future sustainability. It is these elements of an ecosystem that have led us to follow a recent trend in the evidence field to borrow the term from environmental science and describe the evidence-informed decision-making system in South Africa as an 'evidence ecosystem'. In doing so, we define the evidence ecosystem as:

A system reflecting the formal and informal linkages and interactions between different actors (and their capacities 
and resources) involved in the production, translation, and use of evidence.

We set out in this work not only to describe the South African evidence ecosystem but also to reflect on its resilience. We describe this resilience irrespective of political context and changing government administrations. We are not denying that politics matters, but in this work we focus on the aspects of policy-making systems that seem to endure regardless of the party in office, or individuals in key positions. There is an interrelationship between complexity in an environmental ecosystem and its resilience. Resilience is viewed as an emerging property of complexity or a complex adaptive system, as synergies are created in an unplanned way through interactions and interdependences (Dahlberg, 2015). Resilience is also described not only as an ability to 'bounce back' when under threat, but as a potential to adapt for the future, learning and transforming, responding to the opportunities that any disturbance opens up (Folke, 2016). We reflect on indications of the resilience within the South Africa evidence ecosystem.

\section{Methods}

This work is shaped by our combined experience and the position from which we have come to work. It draws on over two decades working within South Africa's evidence ecosystem. Over this time, we have all played many roles including:

- Champions for evidence-informed decision-making and its value;

- Producers of and advocates for the methods of systematic reviews towards co-designing the idea of responsive evidencebases for policy-making;

- Designers and leaders of externally funded evidence capacitybuilding programmes towards supporting the embedding of evidence-informed decision-making capacities within public sector organisations;

- Evidence networkers and relationship builders; and

- Knowledge translators and brokers spanning traditional boundaries between research production and use, across fields and disciplines, between government, academia and civil society, and between advocates of different types of evidence.

Over time, our roles, which started primarily in either research or policy development as two separate paradigms, have migrated towards a middle-ground where research and decisions come together, overlapping with, but not purely focussed on, knowledge translation or sharing. In our work, we recognise that as researchers who wish to see an increase in the use of research evidence in decision-making, we need to understand better the policy process and context, and reprioritise the research that we conduct. As policy-makers, we see the need to seek, define and build an evidence agenda that informs policy, so that research is organised and shared in the way in which policy-makers need evidence. We have seen a significant shift in the role of policymakers, from demanding evidence, to shaping and influencing how evidence is generated, where it is sourced and how it can be used. As such policy-makers are becoming both users and generators of evidence. This begins to shift our thinking away from the two separate paradigms of traditional 'producers' and 'users' of evidence. In all our roles, we are moving from individual projects, towards supporting organisational knowledge structures and processes for evidence use. This framing of our own roles provides the lens through which we view the ecosystem presented in this work.

The findings presented in this article are based on our own observations made over decades of practice, what might be termed as auto-ethnographic observations (Adams et al., 2015). We have also reviewed relevant documentation and conducted discussions with a number of colleagues within the system. Our findings, whilst based on a limited set of data, also present the most complete overview of South Africa's evidence ecosystem and assessment of its resilience to date.

\section{Findings}

Since 1994 South Africa has been on a journey in which evidence and the principles underlying evidence-informed decision-making-those of transparency, accountability and appropriate stewardship of resources to maximise good and avoid harm-are increasingly integrated into the research and policy landscapes. As a result we see several examples of evidence use in both policy formulation and implementation: the most high profile instance of relates to the country's fight against HIV/AIDS. Following a civil society advocacy campaign, the Treatment Action Campaign, an evidence-based approach to the management and care of HIV/AIDS was implemented in the country. The subsequent policy change is estimated to have prevented 1.72 million deaths between 2000 and 2014 (Suthar and Bärnighausen, 2017). In another case, South Africa's social grants system, its design and implementation have been rigorously evaluated in multiple studies. These have found significant positive effects on poverty reduction (Satumba et al., 2017) and women's empowerment (Patel et al., 2015) among other outcomes. In addition to informing prospective policy formulation and design, EIDM in South Africa has also been used to stop and reverse existing policies. For instance, in the education sector, government discontinued the outcome-based education approach once evidence overwhelming indicated its lack of intended outcomes (Lusibi, 2018).

The focus of this article however, is not to analyse in detail the impacts of the evidence ecosystem, but to document the system itself. We consider this documentation an important, and often overlooked, process with value in and of itself. The integration of evidence use in South Africa is evident in a range of activities from embedded government systems, through to externally funded and time-bound activities. In exploring the various elements of this journey, we begin to see the ecosystem as a whole, made up of 5 key elements: structural foundations, organisations, investments, capacities, and innovations. Across these five elements we observe the complexity that gives the system its resilience.

Structural foundations for evidence-informed decision-making in South Africa. Ecosystems rely on sources of energy. South Africa's energy for its evidence ecosystem comes, firstly, from its 1996 Constitution (Republic of South Africa, 1996), and secondly, from two policy areas: one guiding the national research system (Department of Science and Technology, 2019) and the other guiding national planning to meet developmental priorities (National Planning Commission, 2012; Department for Planning, Monitoring and Evaluation, 2015). These build upon, and shape, additional sector-specific institutional legislation and planning. The Constitution lays out an ambitious new structure of government, through which the new South Africa seeks to address its economic, social, political and environmental challenges with transparent and effective administration. Chapter 10 of the Constitution specifies the need to promote 'efficient, economic and effective use of resources' with a public administration that is 'development oriented' (Republic of South Africa, 1996, p. 99). Furthermore, 'transparency must be fostered by providing the public with timely, accessible and accurate information' (Republic of South Africa, 1996, p. 99). As such the Constitution speaks to the will for evidence and its use for public good. 
The political and constitutional drivers for the use of evidence for better policies were enhanced through the adoption of the National Development Plan (NDP). ${ }^{1}$ Lessons learnt globally in striving to meet the Millennium Development Goals, provided a good basis for national governments across the world to develop country-level plans that prioritise developmental objectives. South Africa launched its NDP in 2013 and in the process of finalising it mobilised every sector behind the Plan. The newer global Sustainable Development Goals (SDGs) are currently being interpreted and aligned to development plans internationally, including in South Africa (Casazza, 2016). The NDP reflects on the need for effective policy-making. It puts science and technology at the forefront of South Africa's development, and states its own mandate as 'put(ting) forward solid research, sound evidence and clear recommendations for the government' (National Planning Commission, 2012, p. 480). The NDP has been further embedded through a series of government processes and frameworks, including the Medium-Term Strategic Framework (2014-2019) and the Integrated Planning Bill (Republic of South Africa, 2018) which aligns national objectives to budget priorities in proposed new legislation. These include the Integrated and Comprehensive Monitoring system (Department for Planning, Monitoring and Evaluation, 2017a) and the use of Evaluations and other evidence in implementing the NDP (Department for Planning, Monitoring and Evaluation, 2017b), which documents integrated and formalised use of evidence within the policy planning cycle.

The structural foundation for the evidence ecosystem in South Africa is strengthened by the institutional architecture, with an executive centre that ensures the provisioning and regulation of basic elements of the system. Support and protection of specific elements intended for the broader public good and service, are spread across the system of government that designs, implements and evaluates policy impacts in achieving national objectives. This structure and its interrelationships built between the producers and users of evidence over the years has been at the core of a series of national reviews of progress in realising the objectives that South Africa set for itself since 1994 at ten, fifteen, twenty and twenty-five years since the political transition from apartheid to liberal democracy. In her reflection on the use of evidence as part of the 20-year review, Dayal powerfully concludes on the role of evidence, writing that 'evidence-based policy-making has the potential to develop "administrative will" to empower public officials at all levels with knowledge of public policy processes and social change through effective analysis, thereby facilitating government as a contributor to the knowledge economy' (Dayal, 2016, p. 17).

All in all, there are a number of national institutional-level changes over time that have together set a strong foundation for South Africa's evidence ecosystem. The Constitution, the NDP, related monitoring frameworks to support the institutionalisation of evidence-use, and the series of reviews of progress against national goals, all suggest that South Africa has a strong foundational energy or drive for the use of evidence in decision-making. What we have observed over a relatively short period are more explicit and structured manifestations of an evidence agenda.

\footnotetext{
Organisations (organisms) within the SA evidence ecosystem are the basic building blocks. If we continue with the ecosystem analogy, then we can ask what the key organisms (organisations) are within the system. South Africa's evidence ecosystem finds its roots in the national system of research and innovation. The Department of Science and Technology (DST) ${ }^{2}$ is the custodian of the National System of Innovation (NSI) within which all the
}

different organisations operate. These include the policy-making and advisory levels, as well as funders, producers and users of scientific evidence from public and private sectors. The NSI forms the framework for research policy aimed at reconstructing and building a capable scientific community and ensuring high quality supply of research evidence. Eight statutory science councils, together with the 26 public universities and higher education institutions, and respective funding agencies, collectively provide for a well-developed, functional and internationally recognised national system.

Implementing the initial 1996 White Paper on Science and Technology was not without its challenges and these had direct implications for how evidence was generated and used over the years. The evidence ecosystem, while having strong organisations, was argued to be operating in silos and having little impact on meeting developmental objectives (Department of Science and Technology, 2012a, 2012b). This led to the recent White Paper on Science, Technology and Innovation being based on a broadened understanding of all the actors who belong to the NSI and to develop it towards a more inclusive system (Department of Science and Technology, 2019).

South Africa's annual investment in research and development $(R \& D)$ is assessed by an annual survey and measured by the Gross Expenditure on Research and Development (GERD) as a percentage of GDP. Government funding for R\&D increased by $17 \%$ from $2013 / 14$, representing $43,9 \%$ of total R\&D funding, with the business sector the second largest funder at $40,8 \%$ in 2014/15 (Mail and Guardian, 2017). Although South Africa never met its previous target of $1 \%$ (now 1,5\%), GERD distributed through the National Research Foundation increased from 0,73 to 0,77\% from 2013/14 to 2014/15.

A particular strength of DST's research policy is its strategic investment in capacity. The South African Research Chairs Initiative was established in 2006 as a strategic intervention of the South African government aimed at 'strengthening research and innovation capacity in public universities, enhancing the training of a new generation of researchers and the further development of established researchers in all knowledge areas while responding to national priorities and strategies' (Department for Planning, Monitoring and Evaluation, 2015). These research chairs are awarded funding for five years across all knowledge domains, including science, engineering and technology, as well as social sciences and humanities. The chairs are required to contribute to Masters and $\mathrm{PhD}$ outputs by mentoring students in their fields. Recently, there was a further thrust in awarding 23 new research chairs to women in specific thematic fields, to promote women in science. These chairs operate exclusively or in partnership with a public research institution such as another university, a science council, a national research facility or an academic health complex. Currently, there are 198 research chairs. The establishment of Centres of Excellence since 2004 is also regarded as a key strategic intervention to promote research excellence and international competitiveness, as well provide essential training grounds for new researchers entering the field. To date there are 14 centres headed by South Africa's top-rated researchers and located within universities.

Other strategic initiatives include knowledge interchange and collaboration. Government and the researcher community were working together as early as 2002 when South Africa's Evaluation Network (SAENet) was formed by a group of evaluators from across the country, later to formalise into the South African Monitoring and Evaluation Association (SAMEA). The DST introduced a workshop and seminar programme in 2011, implemented through the Human Sciences Research Council, to facilitate interaction between researchers and policy-makers and strengthen the science-policy interface. Several government 
cluster policy workshops and science seminars were convened from 2011. In the same line, the Academy of Science for South Africa (ASSAf) was founded in 1996 with the mission of promoting and applying scientific thinking in the service of society.

The country's network of 26 public universities produce a growing body of research evidence. These are supported by an increasing number of academic centres and departments that focus specifically on: production of research to inform the achievement of the NDP (such as the Centre of Excellence for Nutrition at the University of the North West); access to research to inform development decision-making (such as the South African SDG Hub); understanding of the policy and planning process (such as the Nelson Mandela School of Public Governance at the University of Cape Town); and the collation of evidence for decision-making (such as the Africa Centre for Evidence at the University of Johannesburg). These policyoriented centres within universities that focus on relevance to government priorities represent a shift away from academic research for research's sake.

Science bodies, including the science councils, and public universities are supported in the process of evidence production with a number of other organisational stakeholders, including mandated national science institutes, some of which have strong relationships with the corresponding government departments, such as the South African National Biodiversity Institute and its work with the Department of Environmental Affairs.

South Africa clearly has a strong, robust and vibrant system for supply of evidence. With concerns though about the ability of the supply side to respond timeously and in an accessible manner to the demands of decision-makers and policy-makers, the South African evidence ecosystem is perhaps unusual in being strongly embedded within structures of government, on the conventional 'demand side'. The appetite amongst South African national government officials for the use of evidence in policy-decisions is growing (Paine-Cronin and Sadan, 2015). Its institutions have formal mandates to operationalise the drivers provided by the Constitution and NDP. As early as 2007, Government had a Monitoring and Evaluation System in place, including elements of citizen monitoring through the use of citizen report cards to monitor service quality. The current central operationalisation of an evidence agenda (as opposed to a science agenda) comes from the Department for Planning, Monitoring and Evaluation (DPME), the government department overseeing policy planning, monitoring and evaluation, formed in 2010. In fact, it has been claimed that the country was one of the earliest adopters of evidence-informed decision-making, and that by 2019, it was the only country that had set up a dedicated government department leading on integrating evidence into the policy-making process, in addition to monitoring and evaluation (Langer et al., 2019). Three specific programmes within DPME generate key monitoring evidence to oversee the performance of government. The National Evaluation System, and the earlier Government Wide Monitoring and Evaluation System, produce critical evidence on publicly funded programmes and interventions to assess relevance and effectiveness. The Management Performance Assessment Tool was launched in 2011 for the assessment and monitoring of national and provincial departments and of the front-line services they provide. The Socio-Economic Impact Assessment System (SEIAS) developed in 2015 requires all policies that go before Cabinet to draw on impact evaluations, as well as other forms of evidence, to make a case for why the policy option is being proposed.

It would be a mistake however, to assume that the use of evidence in government began with or revolves around DPME. Other departments at the centre of government ${ }^{3}$, in particular the
Department for Public Service Administration (DPSA), have been driving strategic and operating standards for public service administration that are core to the structural foundation of South Africa's evidence ecosystem. National Treasury directs and regulates public funds, and specifically guides publicly funded research. In addition, it conducts Performance Expenditure Reviews, and has founded and is funding a Secure Data Facility in partnership with University of Cape Town and South African Revenue Service, where tax administrative data is prepared and curated, specifically for research and policy analysis. These are critical inputs into the evidence ecosystem and are just some of the building blocks at the centre of government that provide the basis of government research infrastructure, necessary for the functioning of the evidence ecosystem. Statistics SA serves as South Africa's national statistical body providing official data to inform economic growth, development, and democracy in the country.

To demonstrate further how the evidence ecosystem is embedded within the demand-space, specific line departments also have a long history of drawing on evidence for decisions that must not be overlooked. Whether explicit or implicit, and not necessarily using the language of 'evidence', this work in many cases pre-dates the NDP and the creation of DPME and provides a foundation to South Africa's evidence ecosystem that is far reaching in scope, in terms of both history and sectoral reach. Several departments have always had in-house scientists who have played important roles in informed policy-development and ensuring engagement with the wider scientific communities

If we look deeper into individual sectors, we can see how the Constitution and the NDP combine with sector-specific legislation and institutional changes to provide a broad foundation for evidence use. For example, the evidence ecosystem within the environment sector is entrenched in the National Environmental Management Act of 1998, the development of which dates back to 1996 and was informed by a broad Consultative Conference on National Environmental Policy (Rossouw and Wiseman, 2004). The Act includes specific wording on the use of available information and has since been supported by additional pieces of legislation including those on biodiversity and on oceans, all of which contain specific commitments to the use of evidence for decision-making. The Department for Environmental Affairs (DEA) has a whole series of evidence strategies and implementation plans and host an annual Biodiversity Research and Evidence Indaba (indaba is a local term for a meeting of leaders). Current government involvement in the evidence ecosystem also extends to the line Departments for Health, Basic Education, Social Development, Human Settlements, Water and Sanitation, Rural Development and Land Reform, and Agriculture, Forestry and Fisheries.

These commitments to evidence-informed decision-making have become more explicit over time. In each of these there are individuals, projects, and in some cases formal functions centred around the use of evidence for better decision-making.

Deepening the evidence system at the provincial and local spheres of government is found in the establishment of research units and/or dedicated officials whose responsibility it is to develop and implement a research agenda for the province. The Western Cape, Gauteng and Limpopo are among those that have invested in research and focussed on research use, through participation in training opportunities and preparation of provincial level evidence plans (Kurian, 2016). Mpumalanga and the Northern Cape have also followed the same path. The current status on the extent to which the provincial evidence ecosystems are functioning though, needs to be explored. Some municipalities, more so the metropolitan cities, are beginning to engage with evidence, although at a limited scale and lesser 
intensities than the national sphere of government. The City of Johannesburg, for example, has partnered with the Gauteng CityRegion Observatory, made up of experts and researchers, to generate city-level evidence for better management.

Viewed as a whole, South Africa's evidence ecosystem features a diverse and established number of organisations driving both demand for and supply of evidence. It is significant that the system is not fragmented into the dichotomy of supply and demand but connected through numerous associations and partnerships amongst the individuals and organisations. We expand further on these connections under section 'Resilience and complexity in South Africa's evidence ecosystem' below.

Investment in the evidence ecosystem. As suggested by the wide range of organisations participating in South Africa's evidence ecosystem, we found that the system is increasingly well resourced. Individual government departments invest in their own evidence production through predominantly commissioned work, and more recently, through establishing posts for researchers and evaluators to undertake in-house work. DST invests in high level publicly funded research programmes and National Treasury, as a central department, invests in evidence through routine government process in monitoring the flow of funds. Individual departments support a range of functions within the evidence ecosystem as mentioned earlier. Although this investment is not consistent, as related to evidence, throughout all levels or spheres of government, with particularly poor and patchy levels of resources at the provincial level, it is none-the-less extra-ordinary to see this level of government commitment to EIDM (Kurian, 2016).

In addition to this, South Africa's evidence ecosystem has benefited from not inconsiderable investment by external bodies: from the United Nations to development agencies, as well as through bilateral and multi-lateral agreements (United Nations, 2015). Examples include the African Union's Development Agency (formerly the New Partnership for Africa's Development), the United Nations International Children's Emergency Fund (UNICEF), and the International Initiative for Impact Evaluation (3ie), as well as the multi-lateral BRICS agreements and bilateral agreement between Malaysia and South Africa. International governments and philanthropic foundations including DFID, USAID, and the Hewlett Foundation have also injected financial support into the ecosystem. Universities and other research bodies also supply seed funding to kickstart new activities, and core funding to sustain them, seen, for example, in the creation of the South African SDG Hub at the University of Pretoria, and the establishment of the Africa Centre for Evidence at the University of Johannesburg.

The Programme to Support Pro-Poor Policy Development (PSPPD) was a European-Union funded programme launched in 2007. This initiative, initially external to government, became increasingly embedded within the National Planning Commission and then the DPME. Its research outputs were used to inform relevant chapters of the NDP, led to the creation of the National Income Dynamics Study, and developed training for senior government officials in evidence-informed policy-making and implementation. Although the initiative officially came to an end in 2015, the legacy of its work is evident in these on-going initiatives.

The UK government's Department for International Development (DFID) funded a number of programmes to Build Capacity to Use Research Evidence (BCURE) from 2014-2016, and South Africa benefited from two of these programmes: The University of Johannesburg-based UJ-BCURE, and a programme known as Vaka Yiko. Both programmes engaged initially with the DPME and the DST to identify needs that they might support. In various ways these initiatives helped to kick start new practices in the use of evidence across government. UJ-BCURE supported colleagues in the Departments for Water and Sanitation, Basic Education, Environmental Affairs, Social Development, Human Settlements, Public Service and Administration, National Treasury, Planning, Monitoring and Evaluation, and Science and Technology, to increase their use of research evidence using a range of mentorship, workshop and relationship-building approaches (Stewart et al., 2017). Whilst the funding for UJ-BCURE came to an end in 2016, the informal cross-government group on evidence continued for a further year. Through its mentorship programme, with the International Initiative for Impact Evaluation (3ie) and with UJ-BCURE team expertise, which led to the conceptualisation and production of policy relevant evidence maps. This work has subsequently systematically constructed the evidence base in five strategic policy areas and continues to date. At around the same time, the World Health Organisation's Alliance for Health Policy and Systems Research supported the Centre for Evidence-based Health Care at Stellenbosch University and their partners to provide support to provincial health officials in South Africa and elsewhere through their Policy Buddies programme (Langlois et al., 2016).

There are also a number of examples of how external activities have helped to move forwards those activities that were already under way within South African government. The second of the DFID-funded BCURE programmes, known as Vaka Yiko, spent three years working with the DEA, offering support to enhance and embed DEA's evidence strategy, which was already in progress prior to the programme, and which benefitted from dedicated support from outside. The Centre for Learning, Evaluation and Results for Anglophone Africa (CLEAR-AA) has been supported for many years by the World Bank, amongst other international funders. It has long legacy of support to the DPME, helping to develop evaluation capacity in the country, amongst other things. Their commitment to systems strengthening is reflected in their approach to support existing work within governments across the continent. In each case, it is demonstrated how opportunities, relationships and policy contexts converge to create sustaining programmes embedded within government or the formal evidence ecosystem.

Another set of investments from internal and external organisations seek to facilitate the spread of information and learning across the South Africa evidence ecosystem and beyond, and wider regional evidence ecosystem. These include the programme to support Development Research Uptake in SubSaharan Africa (DRUSSA) which worked with evidence producers to support better dissemination of research. This time-bound DFID-funded programme, aimed to improve communication of research. Another programme, known as Twende Mbele, is funded by the Hewlett Foundation to build linkages between African countries to maximise learning across the various national evaluation systems in place within governments, and to support newer nascent systems. The Partners for Evidencedriven Rapid Learning for Social Systems (PERLSS) programme, funded by the Hewlett Foundation and Canada's International Development Research Centre, is supporting the development of focussed networks between decision-makers and researchers, and the provision of rapid response services to address policy priorities. On a broader scale the Africa Evidence Network, supported by a number of internal and external funders since 2012, aims to share learning and understanding across the continent reaching all corners of the continent's ecosystems, including South Africa's.

Whilst the length of these investments can vary from a few months to several years, we have seen an increase in the period 
over which funds are committed by external funders. This is matched in many ways by the longer-term investments in the evidence ecosystem by government through integrated systems such as the Government Wide Monitoring and Evaluation System, the National Evaluation System and the SEIAS. The range of funders, not only external, suggest increasing financial stability/sustainability.

In addition, South Africa's evidence ecosystem has benefited from time-bound, often externally resourced, initiatives that have played a number of roles from driving change to sharing learning. They have been drivers of change supporting the wider agendas aligned to the Constitution and the NDP. These can be grouped into initiatives that work with (and sometimes within) government and those that work outside of government. We have also observed a number of activities to bring the internal and external initiatives closer together, including co-production, and increased networking (see section 'Resilience and complexity in South Africa's evidence ecosystem' below for more on this).

Capacities in the ecosystem. South Africa's evidence ecosystem is enabled by a small but growing set of capacities, at both individual and organisational levels. Whilst some individuals stand out for their leadership in and commitment to the use of evidence in decision-making, the system does not rely on only a few champions. Capacity exists at multiple levels and is supported by a range of initiatives (Stewart et al., 2018c).

South Africa benefits from a range of initiatives to build capacity. These range from time-bound initiatives such as BCURE, PSPPD and Policy Buddies mentioned above, to more embedded activities. In addition to more general research production that all universities engage in, there are a number of universities with specialist capacity for the production of evidence to inform decision-making with the explicit aim of supporting South Africa's development priorities. Whilst in many cases this capacity is confined to dedicated units within some universities, it is notable that they are all committed to increasing capacity for the system. It is worth noting that some of the externally funded initiatives have moved on from single time bound grants to become more embedded units within universities. This includes the Africa Centre for Evidence at the University of Johannesburg that was formed as a legacy of the BCURE programme based at the University. This suggests a maturing of those initiatives with greater potential to play a long-term role in the ecosystem.

Since government is increasingly identified as a generator of key evidence for planning, monitoring and evaluating policies and programmes, there is a related focus on building capacity within the broader public administration. The approaches used have evolved from largely one-off workshops to more diverse and institutionalised courses and associated frameworks. Examples include investment by the School of Government in more routine training offerings on evaluation and plans for evidence-informed decisionmaking, building on the pilot course offered for three years by DPME to senior government officials. The focus is also shifted from building individual capability to increasing organisational capacity. DPSA's Knowledge Management Forum, in addition to ensuring norms and standards, is an example of building organisational capacity to store and easily retrieve evidence as needed. Institutional capacity requires more to be done with an increase in the number of agencies and actors in the system.

Capacity, in addition to having grown in depth and scale, is also now more diverse in scope. Capacities are being built across evidence generation methodologies including M\&E, evaluation approaches, evidence synthesis, data innovation, and citizenbased monitoring. In recognition that the ecosystem requires more than just capacity to supply and demand evidence, there are also increasing investments in capacities for organisational change, management for EIDM, and evidence advocacy. And as the connectivity across the ecosystem develops, capacities are also growing in approaches to strengthen these linkages, including capacity for facilitating evidence networks, and for co-producing evidence across the traditional academic and government divide. South Africa benefits from leadership in all of these areas, with increasing cohorts of individuals and organisations with strong evidence literacy and not insignificant abilities.

Innovations and iterations within the ecosystem. Ecosystems have to be adaptive to respond to change. Innovation within the ecosystem is demonstrated through new approaches that capture both the complexities and dynamism of the system. South Africa's evidence ecosystem benefits from innovations at a number of levels, from social innovations, to new methodologies and technologies. In many cases these are the result of numerous iterations of ideas over extended periods of time by a wide range of individuals and organisations.

Social innovations are centred on breaking down silos within South Africa's evidence ecosystem, and working to build trusting relationships. This has been the foundation of a number of initiatives, including UJ-BCURE, PSPPD and the Africa Evidence Network, all mentioned above. They also underlie DPSA's drive to build a network of researchers across government, and the various mentorship approaches that strive to connect academics and government officials in both the legislature and executive. Specific innovations within this broader drive for stronger relationships, include the concept of 'evidence networks' that was arguably developed by Stewart (2018) and has increasingly wide influence as new networks emerge across the continent and further afield. Another very different example is the use of matchmaking in research commissioning used by one of us (DPME, 2016) to facilitate a co-production model for evidence generation. This helped to create a team of experts matched between university and government [including all the authors] collaborating to produce evidence that is both useful and used.

Social innovation has led to methodological innovations. A particularly powerful example within South Africa, is the development of policy-relevant evidence mapping and responsive evidence synthesis services. Building on numerous iterations supported by mentoring approaches and relationship building initiatives, and facilitated by the coproduction approach developed by Dayal, the authors have developed a unique policyrelevant approach to evidence mapping. This innovation was a response to demand for effective, measurable and replicable synthesis of knowledge across the evidence base to inform decision-making within the ecosystem. Together we have adapted systematic review methodology predominantly used in the health sector for application to the social sciences and advanced the evidence gap map methodology that is more commonly employed. Using a co-production approach, we have been able to provide decision-makers with timely systematically collated evidence bases to inform policy development on priority issues. Furthermore, we have developed interactive, user-friendly, visually appealing outputs that put the evidence base at decision-makers' fingertips. The approach values the productive and sharing capacities of academia, knowledge brokers and policy-makers towards meeting common objectives and targets. It is proving to be a policy relevant method of building an evidence base to inform key policy reviews.

These social and methodological innovations have been supported by new technologies that have provided better access to additional data. Specialist software allows better identification, management and visualisation of evidence for decision-making. South Africa's SDG Knowledge Hub provides a central portal of 
repositories from different universities and are organised around the SDG themes. Specialist systematic review software from international organisations such as Cochrane and the EPPICentre enables increasingly efficient management of large amounts of research. The Africa Centre for Evidence's and DPME's respective evidence mapping software applications provide visualisations of evidence-bases for decision-makers in attractive and engaging formats.

Together the many innovations within South Africa's ecosystem are contributing to the embedding of evidence use in the policy making environment.

Resilience and complexity in South Africa's evidence ecosystem. The strength of the South African evidence ecosystem becomes most evident when we consider its complexity, and the resulting resilience within it. Over the last two decades the ecosystem has faced a number of threats, which have at times highlighted the strengths within the system to withstand these threats, and at other times revealed weaknesses. The threats have included the lack of a common agreed understanding of what constitutes evidence, poor management of knowledge within organisations, poor communication of evidence processes between organisations, the provision of poorly thought-through training for individuals that is not sufficiently embedded within organisational capacity, and the tendency to see the use of evidence as a separate activity from routine work practices.

The ecosystem's first defence against such threats lies in the complexity of the system. Simple ecosystems are vulnerable. The more complex a system, the more resilient it is due to its interrelatedness. In our analysis of South Africa's evidence ecosystem, we have identified five dimensions of complexity.

Role-players: complexity in individuals and organisations within the system. The first dimension, and arguably the most complex within South Africa, relates to the individuals and organisations within the system and their increasing inter-connectedness. The number of people within the system with skills, experience and commitment to the ecosystem, as opposed to focusing only on their 'piece of the jigsaw', brings a strength. It is increasingly not the case that if you removed a few key people, the system might grind to a halt. As outlined above, government's role is not insignificant, providing leadership and drivers within the ecosystem. Universities, not-for-profits, international bodies, consultants and donors are all involved. The range of users within government spans South Africa's three arms of the state, namely the legislature, the executive and the judiciary. The judiciary arguably has evidence at its core using the constitution and rights-based framework to defend cases, based on evidence generated for legal purposes. The executive authority rests with the President and Cabinet and, through ministerial leadership of central and line departments, they demand evidence at varying intensities. As already described, the departments' engagement with evidence for decision-making has some depth and some breadth. Largely responding to an accountability agenda, the need for judicious use of public funds drives the Executive's use of evidence. The legislative authority rests with South Africa's Parliament. In the period since 2016 we have seen a rise in the legislature's engagement with evidence, motivated by the abuse of public finance and drive for greater scrutiny.

As hinted at earlier, government engagement at provincial and local levels, in both the legislative and executive functions, is less evident, but not without momentum.

As well as government, there are a range of players, including individuals and organisations that drive the system. The variety in types of organisations has grown steadily with increasing examples of initiatives to support evidence use in decisionmaking by research councils, universities, research consultancies, government departments at all levels, science councils, the School of Government, think tanks, and others. There are indications across these different players that producers, users and intermediaries are gradually moving closer together towards a shared goal of better evidence for better decisions.

It is undeniable that particular individuals stand out in the landscape as playing a key role in the ecosystem. However, our discussions with individuals across the system have highlighted how much many of those in the system invest in building relationships with others (individuals and organisations). The increasing connectivity within the community and between organisations is strengthening the system and increasing its resilience to shocks.

Activities: complexity in the activity spectrum from evidence production to use. The second relates to the complexity of activities that are increasingly playing a role, from production of useful and accessible research, through to the integration of evidence into decision-making processes such as SEIAS, and everything in between. This range of activities has moved on over time, from the production of once-off pieces of relevant research, to programmes for production of relevant research, and then programmes for the systematic synthesis of relevant research, and last but not least, the use of such systematically synthesised evidence.

Sectors: complexity of sectors involved in evidence-informed decision-making. The third dimension is the complexity of sectors involved, from basic education and small business development through to housing and the environment. The complexity of the system is reflected in the number of sectors now engaged deliberatively with evidence and their interconnections and crosslinkages. Perhaps not surprising given the driving force of the NDP, the sectors increasingly reflect the national priorities in tackling poverty and inequality and include: the environmental sector, social development, health, basic education, economic development, science, technology and innovation, land reform, and higher education and training. Whilst the use of evidence across these sectors is by no means universal, the ecosystem is very definitely broader than health. This engagement with evidence-informed decision-making beyond the health sector is, to the best of our knowledge the most far-reaching of any country in Africa.

Types: complexity in evidence types. The fourth dimension of complexity is the wide range of types of evidence playing a part in the ecosystem, and how they are valued. Whilst monitoring and programme evaluation evidence has played a prominent role for a while, in part influenced by investment in this 'profession' from global players such as the World Bank, other types of evidence like citizen evidence, impact evaluations and systematic reviews are also produced. Evidence has been described in government documentation in the following way:

'Evidence should be broadly defined in EBPM [evidencebased policy-making] and what constitutes the most relevant type of evidence differs per policy. At its broadest, evidence can be understood as the available body of facts or information indicating whether a belief or proposition is true or valid.' (Langer et al., 2019, p. 4)

Indeed, the evidence within the South African evidence ecosystem includes monitoring data and administrative data, citizen monitoring data and citizen science more generally, process and impact evaluations, large longitudinal data sets from 
'Birth-to-Twenty', to the National Income Dynamics Study, evidence maps and systematic reviews, to name a few. It reaches beyond South African generated evidence, to embrace relevant evidence from other countries and regions, whether this is global evidence within systematic reviews, or comparative evidence from associated countries such as fellow BRICS members.

Range of questions: complexity in the decision-space for which evidence is sought. The fifth dimension is the range of decisions/ levels of decision-making in which evidence is starting to play a role, from Parliamentary Committees and national dialogues through to local public forums where government processes are only one source. The issues range from central government's concern on theoretical underpinnings-how to conceptualise developmental state architecture? - through to policy formation and implementation with direct local impact-how to design and implement land reform? Civil society in the meantime is seeking evidence to address questions on issues from how to address failures in service delivery, through to how to improve data quality for greater accountability.

In considering these five dimensions of complexity together, we observe inter-relationships within and between them. We have identified partnerships between players and across sectors. For example, formal relationships exist through structures such as the National Evaluation System, and on cross-cutting priority issues such as land reform and human settlements. Research producers also increasingly liaise with one another, for example, through the South African evidence synthesis community, a network including five research centres committed to collating evidence for decision-making. The South African Monitoring and Evaluation Association, as well as the wider African Evaluation Association, bring together professionals across sectors so support the production of useful evaluation evidence. Furthermore, the Africa Evidence Network has an overarching role sharing information and building understanding amongst $2000+$ members from across the continent, supporting relationships and engagements throughout the evidence ecosystem.

Structural changes bring strength to the ecosystem, as well as resources, from the National System of Innovation to the SEIAS process. This evidence infrastructure suggests that long lasting impact is possible, and that the ecosystem is likely to withstand future shocks.

\section{Discussion}

Our findings demonstrate that South Africa's evidence ecosystem has strong structural foundations for evidence-informed decisionmaking, starting with its Constitution and National Development Plan and supported by its National System for Innovation. South Africa is noteworthy for the strength of the demand for evidence, particularly in government. Its evidence ecosystem is made up of many different organisations and initiatives, with significant investment from government, academia and others within the country, which are further supported by external initiatives and financing. The capacity across individuals and organisations is not insignificant and growing steadily. Iterations of evidence initiatives are increasingly embedded within the system through social, methodological and technological innovations. The resilience within the ecosystem is supported by increasing complexity in five dimensions: complexity of role-players, of activities, of sectors, of types of evidence and of the range of questions for which evidence is sought.

The many strengths of the system need to be viewed alongside the limitations of skills and resources in many areas, particularly beyond national government, in civil society and in large sections of the research infrastructure. It is important to acknowledge that despite the many promising elements of South Africa's evidence ecosystem that we have identified and are privileged to work within, there are a number of significant risks to its resilience and sustainability. Evidence production and use is not mainstreamed across all sectors and within critical decision-spaces, nor is the whole of government explicitly engaged in evidence-informed decision-making processes for either policy-making or policyimplementation. Strong silos are experienced still too often, stifling the potential to build relationships. There are challenges with access to evidence and the skills to make sense of it. This is very much the case for some departments and for many working at sub-national and local levels. Access to relatively routine data and research, even when produced within government, remains a problem for many. Knowledge systems are poorly resourced in many cases and poorly managed and there is a need for much more training and support for those within the system. Even where evidence is routinely used for decision-making, and however promising the policy decisions might be, implementation remains fundamental and problematic. Due to the legacy of apartheid policies there is a historic imbalance in how research institutions are resourced and (dis)connected to government, and many research institutions remain largely irrelevant as a result. We have observed a lack of willingness within the research sector to engage and support government, perpetuated by a lack of incentives for academics to conduct policy-relevant and practicerelevant research. In addition, the generation and use of evidence by civil society is patchy, poorly documented, and often neglected. These not insignificant limitations highlight the need for more systems thinking, greater coordinating of efforts and more strategic planning in the evidence ecosystem.

In conducting our analysis, we recognise that there are limitations in our approach. This work is written by a small number of people. By definition this means there are missing details and nuances. We do not have recent experience of civil society's production and use of evidence, and draw from the networks and media on Parliamentary engagement with evidence. We are also pro-evidence and looking to highlight the strengths that we identify within the ecosystem. This is not to say that there are not significant weaknesses within it. We are none-the-less encouraged by the growing resilience in the ecosystem. Amongst our authorship, we acknowledge that we work increasingly in the middle-ground between traditional producers and users of evidence, and we are also reassured to find that this middle ground is also an increasingly prominent feature of South Africa's evidence ecosystem. This article in itself also represents a shift towards system thinking: the days of being able to work in silos are limited. Reflecting more widely, we acknowledge that our perspective of the ecosystem comes from our particular disciplines and approaches, and that there are others who play a role in the ecosystem from very different perspectives, including those who focus on the science-policy interface and other approaches such as government science advisors, and the approach to global evidence assessments used by the Intergovernmental Science-Policy Platform on Biodiversity and Ecosystem Services, and their Intergovernmental Platform on Climate Change.

As the wider context in which the evidence ecosystem operates changes all the time, so the ecosystem needs to continuously adapt and develop. This article reflects on developments in the past and presents the current situation. Things may well change in the future. The potential for change does challenge the resilience in the ecosystem: there are still vulnerabilities and threats within it. The global political environment and its post-fact and post-truth climate provide both a threat and an opportunity, as evidence-informed decision-making stands out as an alternative way of thinking and of making decisions that challenges the status quo. 
The growth of a stronger evidence ecosystem presented in this article is not unique to South Africa. Other countries in the region are also working to build resilient systems, and we are learning from one another in this regard. Examples include work in Burkina Faso (Ridde and Yaméogo, 2018; Zida et al., 2018), Kenya (Jessani et al., 2017), Uganda (Nabyonga-Orem and Mijumbi, 2015); and so much more. This is increasing our collective resilience. As a region we have experienced over the last decade a particular externally driven approach to evidence that rests on the monitoring and evaluation of programmes to assess their efficiencies (Basheka and Byamugisha, 2015). Using an ecosystem lens allows us to consider a more holistic and southern-led interpretation of evidence and its generation and use.

Returning to the opening challenge that the South is not merely a recipient of an evidence-based approach driven from the North, there are a number of lessons that can be drawn out from the South African system which we have described for the wider evidence community, whether in the North or the South.

Overall, we have observed how many of the moral arguments for EIDM are reinforced by the social and political contexts in South Africa, and we propose this is true for the global South as a whole. These include the particular importance of avoiding any waste of resources on ineffective programmes in resource constrained contexts, where the opportunity cost to wasting money is high-the South cannot afford to waste resources. Furthermore, vulnerable groups in poorer countries depend much more on the provision of public services as they cannot afford private options: the empowerment potential of EIDM in poorer contexts is considerable. Developing countries often have lower levels of trust in public institutions given the relatively young age of these institutions, coupled with very real issues of corruption. Building trust in institutions through transparency and open use of evidence therefore has wider spill-over effects. It is not surprising, therefore that comparatively, where many developed countries have moved very slowly in institutionalising EIDM over the last decade, Southern countries such as South Africa seem to be moving much quicker.

Our exploration of the South African evidence ecosystem also suggests that because the need for EIDM is greater in the South, and because the resources and capacities are constrained, we see greater innovation in the South than in the North. Whilst our Northern colleagues might take time (years) to debate which form of meta-analysis is the more rigorous approach for synthesising an evidence-base, in the context of South Africa, there are often few studies for any meta-analysis, and limited skills and software to support such analysis. Despite this, the considerable drivers of poverty and inequality mean that evidence-based approaches are needed quickly, and innovation therefore follows. This may well also mean that evidence ecosystems in the South are more flexible than in the North. Rules and evidence hierarchies are not often emphasised in the South because everyone understands the need for innovation and flexibility given the challenging contexts and lack of resources.

As well as innovation, our experience in South Africa suggests that Southern contexts might be more likely to engage in crosslearning and collaboration. We know of evidence networks and partnerships in the South such as the Africa Evidence Network and the Twende Mbele programme, but to our knowledge there are no American or European-wide evidence networks. Our hypothesis is that where the public sector is a key tool for development, such as in the case of South Africa's National Development Plan, countries are more willing to share experiences and collaborate in building structures for effective public services.

Our analysis of South Africa's system has also highlighted that knowledge systems are globally skewed in favour of the North, where there is more research funding and greater research output. We propose that building strong EIDM systems in Southern countries is likely to see new incentives to invest in local research capacity. That is, policy-makers in Southern countries wanting to use evidence are increasingly frustrated when there is no evidence from their contexts, which may well lead to incentives for funding local research and building research capacities. We have seen in South Africa that as policy-makers engage with EIDM they increase their confidence in, and drive for, quality locally relevant evidence. As policy-makers engage with EIDM in the South they are therefore also more likely to push back on expensive (often external and international) consultants who offer advice to Southern governments. Local capacities can only be sustained if there is opportunity to transform available and accessible evidence into knowledge, using local experiences and interpretations of what works, for whom and under what conditions, supported by a vibrant and thriving evidence ecosystem. The global North can learn from local and indigenous knowledge systems (in our case the spirit of 'Ubuntu'), that has the power to question the legitimacy of any evidence that is outside of the paradigm of lived experiences.

In contextualising models and approaches, our experience has shown that the bedrock of the strength and resilience of an evidence ecosystem lies in the very processes undertaken in generating or sourcing this evidence, and in understanding the evidence landscape with its many actors, even before thinking about its use. This requires consensus building and collective leadership by design in bringing together complementary skills and effective management of resources. If we really want the South to overcome this deficit model, we need to move beyond mere adoption of 'participatory approaches' as a proxy to facilitate evidence use. The existence of an evidence ecosystem that is thriving despite political changes, shows that we need to address the real politics and governance challenges behind evidence production and the power imbalances within the South (as well between the North and South).

Last but not the least, our exploration of the South African evidence ecosystem has confirmed our position that evidence production, and its use in decision-making is not a uniquely Northern endeavour: it neither needs to be 'translated' for the South, nor 'decolonised' in that translation. Lessons are available from across the world, North and South: what perhaps needs greatest adjustment is not the capacities of the South, but the culture that gives global prominence to Northern innovation and leadership but is silent on what is happening in the South. We have noted considerable shifts in this quiet, for example, before the Africa Evidence Network, there was no Africa-driven continental space to talk about evidence. This paper itself is one small step in shifting the balance.

As we reflect on what next for the evidence ecosystem in South Africa, we acknowledge the need to better understand and integrate those parts of the South African system that are currently neglected, such as local and provincial government, and civil society. Closer examination of the implementation of policy decisions, and not just the decisions themselves, is paramount if evidence is to make a real difference in people's lives. Given the suspicion with which new democracies may view evidenceinformed decision-making, as laid out in the introduction, funding home-grown initiatives and/or seeking to enhance existing government programmes is a constructive and meaningful investment for external funders wanting to support South Africa's ecosystem. Last but not least, we observed an impetus to invest more in network facilitation and relationship-building, and recognise that trust is at the heart of novel approaches such as match making and co-production. Stewart $(2015,2018)$ has argued that strong relationships and networks are at the heart of 
evidence-informed decision-making, and that evidence networks make a difference through building shared understanding across the evidence ecosystem, enabling growth in shared capacities, and enabling potential and readiness for change. If you can build trust within the evidence ecosystem, you are increasing the potential to make a real difference through greater understanding (of policy, of evidence, and of how evidence can enable better policies and their implementation) and through reducing silos and increasing collaboration.

Even though motivated by self-determination, South Africa, like other countries on the continent, is challenged to compete with the global movement for social change. We witness increased efforts in the formation of South-South relations in an attempt to strengthen and chart a collective way forward in recognising the contributions made by countries of the South. This article provides only a glimpse of how an evidence ecosystem at a country level cannot be fully understood and appreciated without locating it in the context of a political and knowledge economy. Our analysis of South Africa's evidence ecosystem shows that the global movement can certainly learn from the South. Further comparative analysis will shed further light on similarities and differences across the world. The lessons will be made stronger when many more countries from the South can take a reflective review of their own evidence ecosystems and build this knowledge base.

\section{Data availability}

Data sharing is not applicable to this paper as no datasets were generated or analysed during the current study.

Received: 3 May 2019 Accepted: 23 July 2019

Published online: 13 August 2019

\section{Notes}

1 It is worth noting that former Minister Trevor Manuel, who played a pivotal role in the development of South Africa's National Development Plan, remains a player within South Africa's evidence ecosystem, reflected in his keynote in 2017 to the Global Evidence Summit in Cape Town. [Watch his keynote at https://www.youtube.com/ watch?time_continue $=4 \& \mathrm{v}=\mathrm{GfbZyEQqZQ8}]$

2 Since this work was written, South Africa has had a national election and in the formation of the new government a number of national departments have been merged and renamed. We have decided to keep the former names (prior to 29th May 2019): the developments described in this article took place under the old departmental formulations.

3 The national centre of government refers to "the institution or group of institutions that provide direct support to a country's chief executive" (Alessandro et al., 2013). In South Africa, these have included the Department for Planning, Monitoring and Evaluation, the Department for Public Service Administration, National Treasury, and the Department of Cooperative Governance and Traditional Affairs.

\section{References}

Adams TE, Holman Jones S, Ellis C (2015) Auto-ethnography: understanding qualitative research. Oxford University Press, New York

Alessandro M, Lafuente M, Santiso C (2013) The role of the center of government (Technical note no. IDB-TN-581). Inter-American Development Bank, Washington DC

Basheka BC, Byamugisha A (2015) The state of Monitoring and Evaluation (M\&E) as a discipline in Africa. Afr J Public Aff 8(3):75-95

Casazza A (2016) Aligning the sustainable development goals to the NDP: towards domestication of the SDGs in South Africa. Report. Wits School of Governance, Johannesburg

Dahlberg R (2015) Resilience and complexity: conjoining the discourses of two contested concepts. Cult Unbound 7:541-557

Davies HTO, Nutley SM, Smith PC (1999) Viewpoint: editorial: what works? The role of evidence in public sector policy and practice. Public Money Manag 19 (1):3-5
Dayal H (2016) Using evidence to reflect on South Africa's 20 years of democracy: insights from within the policy space. Knowledge Sector Initiative Working Paper 7

Department of Planning, Monitoring and Evaluation (2015) Diagnostic of Research in DPME. First draft report. Department of Planning, Monitoring and Evaluation, Pretoria

Department of Planning Monitoring and Evaluation (2016) Policy relevant evidence maps-a departmental guidance note. Department of Planning, Monitoring and Evaluation, Pretoria

Department of Planning Monitoring and Evaluation (2017a) Concept note on an integrated and comprehensive monitoring system for the Government of South Africa. Department of Planning, Monitoring and Evaluation, Pretoria

Department of Planning Monitoring and Evaluation (2017b) Concept note on DPME evaluations and other evidence. Department of Planning, Monitoring and Evaluation, Pretoria

Department of Science and Technology (2012a) SA National Survey of Research and Experimental Development: Main Analysis Report 2011/12. Department of Science and Technology, Pretoria

Department of Science and Technology (2012b) Ministerial review committee on the science, technology and innovation landscape in South Africa. Department of Science and Technology, Pretoria

Department of Science and Technology (2019) White paper on science, technology and innovation. Department of Science \& Technology, Pretoria

Elliott JH, Turner T, Clavisi O, Thomas J, Higgins JPT, Mavergames C, Grue RL (2014) Living systematic reviews: an emerging opportunity to narrow the evidence-practice gap. PLOS Med 11(2):e1001603

Folke C (2016) Resilience (Republished). Ecol Soc 21(4):44

Guyatt G, Cairns J, Churchill D et al. (1992) Evidence-based medicine: a new approach to teaching the practice of medicine. J Am Med Assoc 268(17):2420-2425

International Monetary Fund (2018) World economic outlook. IMF, Washington

Jessani N, Kennedy C, Bennet S (2017) Enhancing evidence-informed decisionmaking: strategies for engagement between public health faculty and policymakers in Kenya. Evid Policy 13(2):225-253

Jordaan S, Stewart R, Erasmus Y, Maluwa L, Mitchell J, Langer L, Wildeman R, Tannous N, Koch J (2018) Reflections on mentoring experiences for evidence-informed decision-making in South Africa and Malawi. Dev Pract 28(4):456-467

Kurian M (2016) A Synthesis Report on the positioning of research in the context of Evidence-Based Policy Making (EBPM) in selected provinces and national departments in South Africa. Program to Support pro-Poor Policy Development (PSPPD II), Pretoria

Langer L, Ncube L, Stewart R (2019) Evidence-based Policy-Making in South Africa: using the best available evidence to inform the execution and implementation of the NDP. Department for Planning, Monitoring and Evaluation, Pretoria

Langlois EV, Montekio VB, Young T, Song K, Alcalde-Rabanal J, Tran N (2016) Enhancing evidence informed policymaking in complex health systems: Lessons from multi-site collaborative approaches. Health Res Policy Syst 14:20

Lusibi CR (2018) Evidence for policy making and implementation course. An interview. https://www.youtube.com/watch? $\mathrm{v}=$ gf2CRAcXaqE\&feature=youtu.be

Mail \& Guardian (2017, 21 April) Survey reveals state of R\&D expenditure

Mijumbi RM, Oxman AD, Panisset U, Sewankambo NK (2014) Feasibility of a rapid response mechanism to meet policymakers' urgent needs for research evidence about health systems in a low-income country: a case study. Implement Sci 9:114

Nabyonga-Orem J, Mijumbi R (2015) Evidence for informing health policy development in Low-income Countries (LICs): perspectives of policy actors in Uganda. Int J health policy Manag 4(5):285-293

National Planning Commission (2012) National development plan 2030: our future-make it work. The Presidency, Pretoria

Oliver S, Bangapan M, Stansfield C, Stewart R (2015) Capacity for conducting systematic reviews in low- and middle-income countries: a rapid appraisal. Health Res Policy Syst 13:23

Oronje RN, Zulu EM (2018) Contribution of a network of parliamentary committees of health to the ecosystem of evidence use in African parliaments. Evid Policy 14(3):523-535

Paine-Cronin G, Sadan M (2015) Use of evidence in policy-making in South Africa: an exploratory study of attitudes of senior government officials. Afr Eval J 3(1):a145

Patel L, Knijn T, Van Wel F (2015) Child support grants in South Africa: a pathway to women's empowerment and child well-being? J Soc Policy 44 (2):377-397

Republic of South Africa, RSA (1996) Constitution of South Africa. The Consitutional Assembly, Cape Town

Republic of South Africa (2018) Integrated planning framework Bill. Proposed by Department of Planning Monitoring and Evaluation, Pretoria 
Ridde V, Yaméogo P (2018) How Burkina Faso used evidence in deciding to launch its policy of free healthcare for children under five and women in 2016. Pal Commun 4(1):119

Rossouw N, Wiseman K (2004) Learning from the implementation of environmental public policy instruments after the first ten years of democracy in South Africa. Impact Assess Proj Apprais 22(2):131-140

Satumba T, Bayat A, Mohamed S (2017) The impact of social grants on poverty reduction in South Africa. J Econ 8(1):33-49

Shepherd J (2014) How to achieve more effective services: the evidence ecosystem (Project report). What Works Network, Cardiff

Stewart R (2015) A theory of change for capacity-building for the use of research evidence by decision-makers in southern Africa. Evid Policy 11 (4):547-557

Stewart R (2018) Do evidence networks make a difference? J Dev Eff 10(1):171-178

Stewart R, Erasmus Y, the UJ-BCURE team (2017) Working for solutions: a problem-based and relationship-centred approach to building capacity to use research evidence inAfrica. Africa Centre for Evidence, Johannesburg

Stewart R, Langer L, Wildeman R, Erasmus Y, Maluwa LG, Jordaan S, Lötter D, Mitchell J, Motha P (2018a) Building capacity for evidence-informed decision-making: an example from South Africa. Evid Policy 14(2):241-258

Stewart R, Wildeman R, Jordaan S, Erasmus Y, Langer L, Maluwa L, Tannous N, Mitchell J (2018b). Practical reflections on combining workshops and mentorships to build capacity in demand and use of evidence in government organisations. Evidence Policy 15(2):265-279. https://doi.org/10.1332/ $174426417 X 15090121536975$

Stewart R, Langer L, Erasmus Y (2018c) An integrated model for increasing the use of evidence by decision-makers for improved development. Dev South Afr 1-16. https://doi.org/10.1080/0376835X.2018.1543579

Suthar AB, Bärnighausen T (2017) Antiretroviral therapy and population mortality: leveraging routine national data to advance policy. PLoS Med 14(12): e1002469

United Nations (2015) Transforming our world: the 2030 agenda for sustainable development. Resolution adopted by the General Assembly, New York. United Nations, New York

White $\mathrm{H}$ (2019) The twenty-first century experimenting society: the four waves of the evidence revolution. Pal Commun 5(1):47

World Bank (2018) World development indicators. https://databank.worldbank. org $/$ data/reports.aspx?source $=2 \&$ series $=$ SI.POV.GINI\&country $=\#$. Accessed 3 May 2019
Zida A, Lavis JN, Sewankambo NK, Kouyate B, Ouedraogo S (2018) Evaluating the process and extent of institutionalization: a case study of a rapid response unit for health policy in Burkina Faso. Int J Health Policy Manag 7(1):15-26

\section{Acknowledgements}

The perspectives offered in this work are those of the authors and do not necessarily reflect the views of the University of Johannesburg nor the South African Department of Planning, Monitoring and Evaluation. The authors wish to acknowledge and thank Nkululeko Tshabalala for his assistance on the South African evidence ecosystem assessment, as well as Mapula Tshangela and Shanil Haricharan for constructive feedback on an earlier draft of this work.

\section{Additional information}

Competing interests: All authors are employed by organisations invested in supporting the use of evidence in decision-making in South Africa.

Reprints and permission information is available online at http://www.nature.com/ reprints

Publisher's note: Springer Nature remains neutral with regard to jurisdictional claims in published maps and institutional affiliations.

\begin{abstract}
cc (i) Open Access This article is licensed under a Creative Commons Attribution 4.0 International License, which permits use, sharing, adaptation, distribution and reproduction in any medium or format, as long as you give appropriate credit to the original author(s) and the source, provide a link to the Creative Commons license, and indicate if changes were made. The images or other third party material in this article are included in the article's Creative Commons license, unless indicated otherwise in a credit line to the material. If material is not included in the article's Creative Commons license and your intended use is not permitted by statutory regulation or exceeds the permitted use, you will need to obtain permission directly from the copyright holder. To view a copy of this license, visit http://creativecommons.org/ licenses/by/4.0/.
\end{abstract}

(C) The Author(s) 2019 